\title{
Some new results on fixed and best proximity points in preordered metric spaces
}

\author{
Alireza Amini-Harandi 1,2, Majid Fakhar ${ }^{2,3}$, Hamid Reza Hajisharifi ${ }^{3}$ and Nawab Hussain ${ }^{4 *}$ \\ Dedicated to Professor Wataru Takahashi on the occasion of his seventieth birthday
}

"Correspondence:

nhusain@kau.edu.sa

${ }^{4}$ Department of Mathematics, King

Abdulaziz University, P.O. Box 80203

Jeddah, 21589, Saudi Arabia

Full list of author information is

available at the end of the article

\begin{abstract}
In this paper, we first introduce two new classes of $(\omega, \delta)$-contractions of the first and second kinds and establish some related new fixed point and best proximity point theorems in preordered metric spaces. Our theorems subsume the corresponding recent results of Samet (J. Optim. Theory Appl. (2013), doi:10.1007/s10957-013-0269-9) and extend and generalize many of the well-known results in the literature. An example is also provided to support our main results.
\end{abstract}

MSC: $47 \mathrm{H} 10 ; 41 \mathrm{~A} 65$

Keywords: fixed point; best proximity point; $P$-property; $(\omega, \delta)$-contraction; preordered metric space

\section{Introduction and preliminaries}

Given a metric space $(X, d)$ and a self-mapping $T$ on $X$, the theory on the existence of a solution to the equation of the form $T x=x$ has gained impetus because of its applicability to solve many interesting problems that can be formulated as ordinary differential equations, matrix equations etc. For some recent fixed point results, see [1-6] and references therein. Let $A$ and $B$ be nonempty subsets of $X$, and let $T: A \rightarrow B$ be a non-self mapping. The equation $T x=x$ is unlikely to have a solution, because of the fact that a solution of the preceding equation demands the nonemptiness of $A \cap B$. Eventually, it is quite natural to seek an approximate solution $x$ that is optimal in the sense that the distance $d(x, T x)$ is minimum. The well-known best approximation theorem, due to Fan [7], states that if $A$ is a nonempty, compact, and convex subset of a normed linear space $X$ and $T$ is a continuous function from $A$ to $X$, then there exists a point $x$ in $A$ such that $\|x-T x\|=d(T x, A)=\inf \{\|T x-u\|: u \in A\}$. Such a point $\mathrm{x}$ is called a best approximant point of $T$ in $A$. Many generalizations and extensions of this theorem appeared in the literature (see [8-11] and references therein).

Best proximity problem for the pairs $(A, B)$ is to find an element $x \in A$ such that $d(x, T x)=$ $d(A, B)$, where $d(A, B)=\inf \{d(x, y): x \in A, y \in B\}$. Since $d(A, B)$ is a lower bound for the function $x \rightarrow d(x, T x)$ on $A$, then the solutions of the best proximity problem are the minimum points of the function $x \rightarrow d(x, T x)$ on $A$. Every solution of the best proximity problem is said to be a best proximity point of $T$ in $A$. Moreover, if $A=B$ then every best proximity point of $T$ is a fixed point. According to this fact, many authors by motivation of well-known fixed point results obtained sufficient conditions to solving best proximity problems; for more details, see [12-27] and the references therein.

@2013 Amini-Harandi et al.; licensee Springer. This is an Open Access article distributed under the terms of the Creative Commons Attribution License (http://creativecommons.org/licenses/by/2.0), which permits unrestricted use, distribution, and reproduction in any medium, provided the original work is properly cited. 
Existence of best proximity and fixed points in partially ordered metric spaces has been considered recently by many authors (see [6, 13, 20, 28]). Recently Samet [29] studied the existence of best proximity points for a class of non-self almost $(\varphi, \theta)$-contractive mappings. In this work we define two new classes of contractions called $(\omega, \delta)$-contractions of the first and second kind and establish some related new fixed point results in the setting of preordered metric spaces, and then we derive some new best proximity point theorems for these new classes of non-self contractive mappings. The presented theorems extend and generalize many of the well-known fixed point and best proximity point results.

\section{Fixed point theory}

Definition 2.1 Let $(X, d)$ be a metric space, and let $R_{+}=[0, \infty)$.

(a) Denote by $\Omega$ the family of functions $\omega: R_{+} \rightarrow R_{+}$such that $\omega(0)=0, \omega(t)<t$ for each $t>0$ and for each sequence $\left\{x_{n}\right\}$ in $X$ with,

$$
d\left(x_{n}, x_{n+1}\right) \leq \omega\left(d\left(x_{n-1}, x_{n}\right)\right) \quad \forall n \in \mathbb{N} \Rightarrow\left\{x_{n}\right\} \text { is a Cauchy sequence; }
$$

(b) Denote by $\Delta$ the family of functions $\delta: R_{+}^{4} \rightarrow R$ such that $\delta$ is continuous and if $t_{i}=0$ for some $i \in\{1,2,3,4\}$, then $\delta\left(t_{1}, t_{2}, t_{3}, t_{4}\right)=0$;

(c) Denote by $\Phi$ the family of non-decreasing functions $\phi: R_{+} \rightarrow R_{+}$such that $\Sigma_{n=1}^{\infty} \phi^{n}(t)<\infty$ for each $t>0$;

(d) Denote by $\Sigma$ the family of functions $\sigma: R_{+} \rightarrow R_{+}$such that $\sigma(t)=\alpha(t) t$ for each $t>0$ and $\alpha: R_{+} \rightarrow[0,1)$ satisfies

$$
\limsup _{s \rightarrow t} \alpha(s)<1 \quad \text { for each } t>0
$$

(e) Denote by $\Psi$ the family of non-decreasing functions $\psi: R_{+} \rightarrow R_{+}$such that $\lim _{n \rightarrow \infty} \psi^{n}(t)=0$ for each $t>0$

(f) Denote by $\Lambda$ the family of non-decreasing and upper semicontinuous from the right functions $\lambda: R_{+} \rightarrow R_{+}$such that $\lambda(t)<t$ for each $t>0$;

(g) Let $\Theta$ be a collection of the following functions:

$$
\begin{aligned}
& \theta\left(t_{1}, t_{2}, t_{3}, t_{4}\right)=\tau \min \left\{t_{1}, t_{2}, t_{3}, t_{4}\right\}, \tau>0 ; \\
& \theta\left(t_{1}, t_{2}, t_{3}, t_{4}\right)=\tau \ln \left(1+t_{1} t_{2} t_{3} t_{4}\right), \tau>0 ; \\
& \theta\left(t_{1}, t_{2}, t_{3}, t_{4}\right)=\tau t_{1} t_{2} t_{3} t_{4}, \tau>0 .
\end{aligned}
$$

Lemma 2.2 Let $(X, d)$ be a metric space. Then the following statements hold:

(i) $\Phi \subseteq \Omega$,

(ii) $\Sigma \subseteq \Omega$,

(iii) $\Psi \subseteq \Omega$,

(iv) $\Lambda \subseteq \Psi \subseteq \Omega$,

(v) $\Theta \subseteq \Delta$.

Proof Let $\left\{x_{n}\right\}$ be a sequence in $X$. To prove (i), assume that $d\left(x_{n}, x_{n+1}\right) \leq \phi\left(d\left(x_{n-1}, x_{n}\right)\right)$ for each $n \in \mathbb{N}$, where $\phi \in \Phi$. Since $\phi$ is non-decreasing, then by induction we get

$$
d\left(x_{n}, x_{n+1}\right) \leq \phi^{n}\left(d\left(x_{0}, x_{1}\right)\right) \quad \text { for each } n \in \mathbb{N} \text {. }
$$


Then, for each sufficiently large $m<n$, we have

$$
d\left(x_{m}, x_{n}\right) \leq \sum_{j=m}^{n-1} d\left(x_{j}, x_{j+1}\right) \leq \sum_{j=m}^{n-1} \phi^{n}\left(d\left(x_{0}, x_{1}\right)\right)<\epsilon,
$$

and so $\left\{x_{n}\right\}$ is a Cauchy sequence.

(ii) Let us suppose that $d\left(x_{n}, x_{n+1}\right) \leq \sigma\left(d\left(x_{n-1}, x_{n}\right)\right)$ for each $n \in \mathbb{N}$, where $\sigma(t)=\alpha(t) t$ for each $t>0$ and $\alpha$ satisfying (1). Then

$$
d\left(x_{n}, x_{n+1}\right) \leq \alpha\left(d\left(x_{n-1}, x_{n}\right)\right) d\left(x_{n-1}, x_{n}\right)
$$

for each $n \in \mathbb{N}$. Since $\alpha(t)<1$ for each $t \in R_{+}$, then $\left\{d\left(x_{n}, x_{n+1}\right)\right\}$ is a non-increasing sequence of non-negative numbers and so is convergent to a real number, say $r_{0}$. We will show that $r_{0}=0$. On the contrary, assume that $r_{0}>0$. Then from (2) we get

$$
1=\lim _{n \rightarrow \infty} \frac{d\left(x_{n}, x_{n+1}\right)}{d\left(x_{n-1}, x_{n}\right)} \leq \limsup _{n \rightarrow \infty} \alpha\left(d\left(x_{n-1}, x_{n}\right)\right) \leq \limsup _{s \rightarrow r_{0}} \alpha(s),
$$

a contradiction and so $r_{0}=0$. To show that $\left\{x_{n}\right\}$ is a Cauchy sequence, on the contrary assume that $\limsup _{m, n \rightarrow \infty} d\left(x_{m}, x_{n}\right)=\infty$. Thus there exist subsequences $\left\{x_{m_{k}}\right\}$ and $\left\{x_{n_{k}}\right\}$ such that $\lim _{k \rightarrow \infty} d\left(x_{m_{k}}, x_{n_{k}}\right)>0$. Then, by the triangle inequality, we get

$$
\begin{aligned}
d\left(x_{m_{k}}, x_{n_{k}}\right) & \leq d\left(x_{m_{k}}, x_{m_{k}+1}\right)+d\left(x_{m_{k}+1}, x_{n_{k}+1}\right)+d\left(x_{n_{k}+1}, x_{n_{k}}\right) \\
& \leq d\left(x_{m_{k}}, x_{m_{k}+1}\right)+\alpha\left(d\left(x_{m_{k}}, x_{n_{k}}\right)\right) d\left(x_{m_{k}}, x_{n_{k}}\right)+d\left(x_{n_{k}+1}, x_{n_{k}}\right) .
\end{aligned}
$$

Then

$$
\left(1-\alpha\left(d\left(x_{m_{k}}, x_{n_{k}}\right)\right)\right) d\left(x_{m_{k}}, x_{n_{k}}\right) \leq d\left(x_{m_{k}}, x_{m_{k}+1}\right)+d\left(x_{n_{k}+1}, x_{n_{k}}\right)
$$

for each $k \in \mathbb{N}$. From the above, we obtain $\lim _{k \rightarrow \infty} \alpha\left(d\left(x_{m_{k}}, x_{n_{k}}\right)\right)=1$. Then from (1) we get $\lim _{k \rightarrow \infty} d\left(x_{m_{k}}, x_{n_{k}}\right)=0$, a contradiction. Therefore, $\left\{x_{n}\right\}$ is a Cauchy sequence.

(iii) Notice first that $\psi(t)<t$ for each $t>0$. To see this, suppose that there exists $t_{0}>0$ with $\psi\left(t_{0}\right)>t_{0}$, then since $\psi$ is non-decreasing, we see that $t_{0} \leq \psi^{n}\left(t_{0}\right)$ for all $n \in \mathbb{N}$ and it is a contradiction with $\lim _{n \rightarrow \infty} \psi^{n}(t)=0$ for each $t>0$. Note also that $\psi(0)=0$.

Now assume that $d\left(x_{n}, x_{n+1}\right) \leq \psi\left(d\left(x_{n-1}, x_{n}\right)\right)$ for each $n \in \mathbb{N}$, where $\psi \in \Psi$. Since $\psi$ is non-decreasing, then by induction we get

$$
d\left(x_{n}, x_{n+1}\right) \leq \psi^{n}\left(d\left(x_{0}, x_{1}\right)\right) \text { for each } n \in \mathbb{N} \text {. }
$$

Let $\epsilon>0$ be fixed. Choose $n \in \mathbb{N}$ such that

$$
d\left(x_{n+1}, x_{n}\right)<\epsilon-\psi(\epsilon) .
$$

Now we have

$$
\begin{aligned}
d\left(x_{n+2}, x_{n}\right) & \leq d\left(x_{n+2}, x_{n+1}\right)+d\left(x_{n+1}, x_{n}\right) \\
& \leq \psi\left(d\left(x_{n+1}, x_{n}\right)\right)+(\epsilon-\psi(\epsilon))
\end{aligned}
$$




$$
\begin{aligned}
& \leq \psi(\epsilon-\psi(\epsilon))+(\epsilon-\psi(\epsilon)) \\
& \leq \psi(\epsilon)+(\epsilon-\psi(\epsilon))=\epsilon .
\end{aligned}
$$

Also we have

$$
\begin{aligned}
d\left(x_{n+3}, x_{n}\right) & \leq d\left(x_{n+3}, x_{n+1}\right)+d\left(x_{n+1}, x_{n}\right) \\
& \leq \psi\left(d\left(x_{n+2}, x_{n}\right)\right)+(\epsilon-\psi(\epsilon)) \\
& \leq \psi(\epsilon)+(\epsilon-\psi(\epsilon))=\epsilon .
\end{aligned}
$$

So, by induction, for each $k \in \mathbb{N}$, we have

$$
d\left(x_{n+k}, x_{n}\right) \leq \epsilon
$$

This implies that $\left(x_{n}\right)$ is Cauchy and the proof of (iii) is complete.

(iv) For each $\lambda \in \Lambda$, we have $\lim _{n \rightarrow \infty} \lambda^{n}(t)=0$ for each $t>0$ (see Remark 2.2 in [30]). Then the conclusion follows from (iii).

(v) obviously holds.

Let $X$ be a nonempty set. A preorder $\preceq$ on $X$ is a binary relation which is reflexive and transitive. Let $(X, \preceq)$ be a preordered set, and let $T: X \rightarrow X$ be a mapping. We say that $T$ is non-decreasing if for each $x, y \in X, x \preceq y \Rightarrow T x \preceq T y$.

Definition 2.3 Let $(X, \preceq)$ be a preordered set and $d$ be a metric on $X$. We say that $(X, \preceq, d)$ is regular if and only if the following condition holds:

$\left\{x_{n}\right\}$ is non-decreasing and $x_{n} \rightarrow x$ for some $x \in X \Rightarrow x_{n} \preceq x$ for each $n \in \mathbb{N}$.

Definition 2.4 Let $(X, \preceq, d)$ be a preordered metric space, and let $\omega: R_{+} \rightarrow R_{+}$and $\delta$ : $R_{+}^{4} \rightarrow R_{+}$be arbitrary mappings.

(a) A mapping $T: X \rightarrow X$ is said to be $(\omega, \delta, \preceq)$-contraction of the first kind if for all $x, y \in X$ with $x \preceq y$,

$$
d(T x, T y) \leq \omega(d(x, y))+\delta(d(x, T x), d(y, T y), d(x, T y), d(y, T x))
$$

(b) A mapping $T: X \rightarrow X$ is said to be $(\omega, \delta, \preceq)$-contraction of the second kind if for all $x, y \in X$ with $x \preceq y$,

$$
d(T x, T y) \leq \omega(M(x, y))+\delta(d(x, T x), d(y, T y), d(x, T y), d(y, T x))
$$

where $M(x, y)=\max \left\{d(x, y), d(x, T x), d(y, T y), \frac{d(x, T y)+d(y, T x)}{2}\right\}$

Remark 2.5 If $\preceq=X \times X$, that is, $x \preceq y$ for each $x, y \in X$, then $(\omega, \delta, \preceq)$-contractions of the first and second kind are called $(\omega, \delta)$-contractions of the first and second kind in brief. The class of $(\omega, \delta)$-contraction maps of the first and second kind include the mappings with condition (B) [3] and almost generalized contractions [6], respectively. 
Theorem 2.6 Let $(X, \preceq, d)$ be a complete preordered metric space, and let $T: X \rightarrow X$ be a mapping. Suppose that the following conditions hold:

(i) $T$ is continuous or $(X, \preceq, d)$ is regular,

(ii) $T$ is non-decreasing,

(iii) there exists $x_{0} \in X$ such that $x_{0} \preceq T x_{0}$,

(iv) $T$ is an $(\omega, \delta, \preceq)$-contraction mapping of the first kind, where $\omega \in \Omega$ and $\delta \in \Delta$.

Then $T$ has a fixed point. Moreover, the sequence $\left\{T^{n} x_{0}\right\}$ converges to the fixed point of $T$.

Proof Let $x_{n}=T x_{n-1}$ for any $n \in \mathbb{N}$. Since $x_{0} \preceq T x_{0}$ and $T$ is non-decreasing, then we have

$$
x_{0} \preceq x_{1} \preceq x_{2} \preceq \cdots \preceq x_{n} \preceq x_{n+1} \preceq \cdots .
$$

Now since $T$ is an $(\omega, \delta, \preceq)$-contraction mapping of the first kind, we get

$$
\begin{aligned}
d\left(x_{n+1}, x_{n}\right)= & d\left(T x_{n}, T x_{n-1}\right) \leq \omega\left(d\left(x_{n}, x_{n-1}\right)\right) \\
& +\delta\left(d\left(x_{n}, T x_{n}\right), d\left(x_{n-1}, T x_{n-1}\right), d\left(x_{n}, T x_{n-1}\right), d\left(x_{n-1}, T x_{n}\right)\right)
\end{aligned}
$$

for all $n \in \mathbb{N}$. Since $d\left(x_{n}, T x_{n-1}\right)=d\left(x_{n}, x_{n}\right)=0$ and $\delta \in \Delta$, so for all $n \in \mathbb{N}$,

$$
\delta\left(d\left(x_{n}, T x_{n}\right), d\left(x_{n-1}, T x_{n-1}\right), d\left(x_{n}, T x_{n-1}\right), d\left(x_{n-1}, T x_{n}\right)\right)=0 .
$$

Now, from (3) and (4), we have

$$
d\left(x_{n+1}, x_{n}\right) \leq \omega\left(d\left(x_{n}, x_{n-1}\right)\right)
$$

for all $n \in \mathbb{N}$. Since $\omega \in \Omega$, so $\left\{x_{n}\right\}$ is a Cauchy sequence, hence there exists $x^{*} \in X$ such that $\left\{x_{n}\right\}$ converges to $x^{*}$. Now we show that $x^{*}$ is a fixed point of $T$. If $T$ is continuous, then from the equality $x_{n}=T x_{n-1}$, we get $x^{*}=T x^{*}$. Now assume that $(X, \preceq, d)$ is regular. Then, for each $n \in \mathbb{N}$, we have $x_{n} \preceq x^{*}$. On the contrary, assume that $d\left(x^{*}, T x^{*}\right)>0$. For any $n \in \mathbb{N}$,

$$
\begin{aligned}
d\left(T x^{*}, x_{n+1}\right) & =d\left(T x^{*}, T x_{n}\right) \\
& \leq \omega\left(d\left(x_{n}, x^{*}\right)\right)+\delta\left(d\left(x_{n}, T x_{n}\right), d\left(x^{*}, T x^{*}\right), d\left(x_{n}, T x^{*}\right), d\left(x^{*}, T x_{n}\right)\right) \\
& \leq d\left(x_{n}, x^{*}\right)+\delta\left(d\left(x_{n}, x_{n+1}\right), d\left(x^{*}, T x^{*}\right), d\left(x_{n}, T x^{*}\right), d\left(x^{*}, x_{n+1}\right)\right) .
\end{aligned}
$$

Since $\lim _{n \rightarrow \infty} d\left(x^{*}, x_{n+1}\right)=\lim _{n \rightarrow \infty} d\left(x_{n}, x_{n+1}\right)=0$ and $\delta \in \Delta$, then

$$
\lim _{n \rightarrow \infty} \delta\left(d\left(x_{n}, x_{n+1}\right), d\left(x^{*}, T x^{*}\right), d\left(x_{n}, T x^{*}\right), d\left(x^{*}, x_{n+1}\right)\right)=0,
$$

and so from (5) we get $x^{*}=T x^{*}$.

Corollary 2.7 Let $(X, d)$ be a complete metric space, and let $T: X \rightarrow X$ be an $(\omega, \delta)$ contraction mapping of the first kind, where $\omega \in \Omega$ and $\delta \in \Delta$. Then

(i) $T$ has a unique fixed point. Moreover, for all $x_{0} \in X$, the sequence $\left\{T^{n} x_{0}\right\}$ converges to the fixed point of $T$, that is, $T$ is the Picard operator.

(ii) $T$ is continuous at $\operatorname{Fix}(T)=\left\{x^{*}\right\}$. 
Proof (i) Let $\preceq=X \times X$. Then from Theorem 2.6 we deduce that $T$ has a fixed point. To prove the uniqueness, on the contrary, assume that $x, y \in X$ are distinct fixed points of $T$. So,

$$
\begin{aligned}
d(x, y) & =d(T x, T y) \leq \omega(d(x, y))+\delta(d(x, T x), d(y, T y), d(x, T y), d(y, T x)) \\
& =\omega(d(x, y))<d(x, y)
\end{aligned}
$$

a contradiction. By the uniqueness of a fixed point and from Theorem 2.6, we get that the sequence $\left\{T^{n} x_{0}\right\}$ converges to the fixed point of $T$ for all $x_{0} \in X$.

(ii) Let $\operatorname{Fix}(T)=\left\{x^{*}\right\}$ and $\left\{y_{n}\right\}$ be a sequence in $X$ such that $y_{n} \rightarrow x^{*}$. Since $T$ is an $(\omega, \delta)$ contraction mapping of the first kind, so for all $n \in \mathbb{N}$ we have

$$
d\left(T x^{*}, T y_{n}\right) \leq \omega\left(d\left(x^{*}, y_{n}\right)\right)+\delta\left(d\left(x^{*}, T x^{*}\right), d\left(y_{n}, T y_{n}\right), d\left(x^{*}, T y_{n}\right), d\left(y_{n}, T x^{*}\right)\right) .
$$

Since $T x^{*}=x^{*}$ and $\delta \in \Delta$, we have

$$
\delta\left(d\left(x^{*}, T x^{*}\right), d\left(y_{n}, T y_{n}\right), d\left(x^{*}, T y_{n}\right), d\left(y_{n}, T x^{*}\right)\right)=0 .
$$

Thus, for any $n \in \mathbb{N}$,

$$
d\left(T x^{*}, T y_{n}\right) \leq \omega\left(d\left(x^{*}, y_{n}\right)\right)<d\left(x^{*}, y_{n}\right) .
$$

Thus $T y_{n} \rightarrow T x^{*}$, and so $T$ is continuous at $x^{*}$.

Remark 2.8 Theorem 2.6 extends the main result of Babu et al. [3], Corollary 1 of Berinde et al. [4], Corollary 3.1 of Samet [29] and Theorem 2.1 of Agarwal et al. [30].

Theorem 2.9 Let $(X, \preceq, d)$ be a complete preordered metric space, and let $T: X \rightarrow X$ be a mapping. Suppose that the following conditions hold:

(i) $T$ is continuous or $(X, \preceq, d)$ is regular,

(ii) $T$ is non-decreasing,

(iii) there exists $x_{0} \in X$ such that $x_{0} \preceq T x_{0}$,

(iv) $T$ is an $(\omega, \delta, \preceq)$-contraction mapping of the second kind, where $\omega \in \Omega$ and $\delta \in \Delta$.

Then $T$ has a fixed point. Moreover, the sequence $\left\{T^{n} x_{0}\right\}$ converges to the fixed point of $T$.

Proof Let $x_{n}=T x_{n-1}$ for any $n \in \mathbb{N}$. If $x_{n-1}=x_{n}$ for some $n \in \mathbb{N}$, then $x_{n-1}=x_{n}=T x_{n-1}$, and so $x_{n-1}$ is a fixed point of $T$, and we are finished. So, we may assume that $d\left(x_{n-1}, x_{n}\right)>0$ for all $n \in \mathbb{N}$. Now, since $x_{0} \preceq T x_{0}$ and $T$ is non-decreasing, so

$$
x_{0} \preceq x_{1} \preceq x_{2} \preceq \cdots \preceq x_{n} \preceq x_{n+1} \preceq \cdots .
$$

Since $T$ is an $(\omega, \delta, \preceq)$-contraction of the second kind, so for all $n \in \mathbb{N}$ we have

$$
\begin{aligned}
d\left(x_{n+1}, x_{n}\right)= & d\left(T x_{n}, T x_{n-1}\right) \leq \omega\left(M\left(x_{n}, x_{n-1}\right)\right) \\
& +\delta\left(d\left(x_{n}, T x_{n}\right), d\left(x_{n-1}, T x_{n-1}\right), d\left(x_{n}, T x_{n-1}\right), d\left(x_{n-1}, T x_{n}\right)\right) .
\end{aligned}
$$


Since $d\left(x_{n}, T x_{n-1}\right)=d\left(x_{n}, x_{n}\right)=0$ and $\delta \in \Delta$, for all $n \in \mathbb{N}$,

$$
\delta\left(d\left(x_{n}, T x_{n}\right), d\left(x_{n-1}, T x_{n-1}\right), d\left(x_{n}, T x_{n-1}\right), d\left(x_{n-1}, T x_{n}\right)\right)=0 .
$$

For all $n \in \mathbb{N}$, we have

$$
M\left(x_{n}, x_{n-1}\right)=\max \left\{d\left(x_{n}, x_{n-1}\right), d\left(x_{n}, x_{n+1}\right), \frac{d\left(x_{n-1}, x_{n+1}\right)}{2}\right\} .
$$

By the triangle inequality, we have

$$
\begin{aligned}
\frac{d\left(x_{n-1}, x_{n+1}\right)}{2} & \leq \frac{d\left(x_{n-1}, x_{n}\right)+d\left(x_{n}, x_{n+1}\right)}{2} \\
& \leq \max \left\{d\left(x_{n}, x_{n-1}\right), d\left(x_{n}, x_{n+1}\right)\right\} .
\end{aligned}
$$

Hence, by (8), (9) and (10),

$$
d\left(x_{n+1}, x_{n}\right) \leq \omega\left(\max \left\{d\left(x_{n}, x_{n-1}\right), d\left(x_{n}, x_{n+1}\right)\right\}\right) .
$$

Now, if $\max \left\{d\left(x_{n}, x_{n-1}\right), d\left(x_{n}, x_{n+1}\right)\right\}=d\left(x_{n+1}, x_{n}\right)$, then by (11) we have

$$
d\left(x_{n+1}, x_{n}\right) \leq \omega\left(d\left(x_{n}, x_{n+1}\right)\right)<d\left(x_{n}, x_{n+1}\right),
$$

a contradiction. So, for all $n \in \mathbb{N}$, we have

$$
d\left(x_{n+1}, x_{n}\right) \leq \omega\left(d\left(x_{n-1}, x_{n}\right)\right) .
$$

As $\omega \in \Omega$, so $\left\{x_{n}\right\}$ is a Cauchy sequence and so, by the completeness of $(X, d)$, there exists $x^{*} \in X$ such that $\left\{x_{n}\right\}$ converges to $x^{*}$. Now we show that $x^{*}$ is a fixed point of $T$. If $T$ is continuous, then from the equality $x_{n}=T x_{n-1}$, we get $x^{*}=T x^{*}$. Now, assume that $(X, \preceq, d)$ is regular. Then, for each $n \in \mathbb{N}$, we have $x_{n} \preceq x^{*}$. Now, on the contrary, assume that $d\left(x^{*}, T x^{*}\right)>0$. So, for any $n \in \mathbb{N}$,

$$
\begin{aligned}
d\left(T x^{*}, x_{n+1}\right) & =d\left(T x^{*}, T x_{n}\right) \\
& \leq \omega\left(M\left(x_{n}, x^{*}\right)\right)+\delta\left(d\left(x_{n}, x_{n+1}\right), d\left(x^{*}, T x^{*}\right), d\left(x_{n}, T x^{*}\right), d\left(x^{*}, x_{n+1}\right)\right) .
\end{aligned}
$$

Since $\lim _{n \rightarrow \infty} d\left(x^{*}, x_{n+1}\right)=\lim _{n \rightarrow \infty} d\left(x_{n}, x_{n+1}\right)=0$ and $\delta \in \Delta$, we have

$$
\lim _{n \rightarrow \infty} \delta\left(d\left(x_{n}, x_{n+1}\right), d\left(x^{*}, T x^{*}\right), d\left(x_{n}, T x^{*}\right), d\left(x^{*}, x_{n+1}\right)\right)=0 .
$$

Now let $a=d\left(x^{*}, T x^{*}\right)$ and choose $n \in \mathbb{N}$ such that for $n \geq N$, we have $d\left(x^{*}, x_{n}\right)<\frac{a}{2}$, then

$$
d\left(x_{n+1}, x_{n}\right) \leq d\left(x^{*}, x_{n+1}\right)+d\left(x^{*}, x_{n}\right)<\frac{a}{2}+\frac{a}{2}=a,
$$

and

$$
\frac{d\left(x_{n}, T x^{*}\right)+d\left(x_{n+1}, x^{*}\right)}{2}<\frac{1}{2}\left(\frac{a}{2}+d\left(x^{*}, T x^{*}\right)+d\left(x^{*}, x_{n}\right)\right)<\frac{1}{2}\left(\frac{a}{2}+a+\frac{a}{2}\right)=a \text {. }
$$


So, for $n \geq N$, we have

$$
\omega\left(\max \left\{d\left(x_{n}, x^{*}\right), d\left(x_{n}, x_{n+1}\right), d\left(x^{*}, T x^{*}\right), \frac{d\left(x_{n}, T x^{*}\right)+d\left(x^{*}, x_{n+1}\right)}{2}\right\}\right) \leq \omega\left(d\left(x^{*}, T x^{*}\right)\right) .
$$

Then, from (12) and (13), we get

$$
\begin{aligned}
d\left(T x^{*}, x^{*}\right)= & \lim _{n \rightarrow \infty} d\left(T x^{*}, x_{n+1}\right) \leq \limsup _{n \rightarrow \infty} \omega\left(M\left(x_{n}, x^{*}\right)\right) \\
= & \limsup _{n \rightarrow \infty} \omega\left(\operatorname { m a x } \left\{d\left(x_{n}, x^{*}\right), d\left(x_{n}, x_{n+1}\right), d\left(x^{*}, T x^{*}\right),\right.\right. \\
& \left.\left.\frac{d\left(x_{n}, T x^{*}\right)+d\left(x^{*}, x_{n+1}\right)}{2}\right\}\right) \\
\leq & \omega\left(d\left(x^{*}, T x^{*}\right)\right)<d\left(x^{*}, T x^{*}\right),
\end{aligned}
$$

a contradiction.

Corollary 2.10 Let $(X, d)$ be a complete metric space, and let $T: X \rightarrow X$ be an $(\omega, \delta)$ contraction mapping of the second kind, where $\omega \in \Omega$ and $\delta \in \Delta$. Then $T$ has a unique fixed point. Moreover, for all $x_{0} \in X$, the sequence $\left\{T^{n} x_{0}\right\}$ converges to the fixed point of $T$, that is, $T$ is the Picard operator.

Proof By Theorem 2.9 it is sufficient to prove the uniqueness of the fixed point. On the contrary assume that $x, y \in X$ are distinct fixed points of $T$. Then

$$
\begin{aligned}
d(x, y) & =d(T x, T y) \leq \omega(M(x, y))+\delta(d(x, T x), d(y, T y), d(x, T y), d(y, T x)) \\
& =\omega(d(x, y))<d(x, y),
\end{aligned}
$$

a contradiction.

Remark 2.11 Theorem 2.9 is a generalization of Theorem 2.2 and Theorem 2.3 of Agarwal et al. [30].

Remark 2.12 When for all $t \in[0, \infty)$ we set $\omega(t)=\alpha t$ where $\alpha \in(0,1)$ and $\delta\left(t_{1}, t_{2}, t_{3}, t_{4}\right)=$ $L \min \left\{t_{1}, t_{2}, t_{3}, t_{4}\right\}$ where $L \geq 0$, in Corollary 2.10, we obtain Theorem 2.4 of Berinde [5].

\section{Best proximity point theory}

Let $A$ and $B$ be two nonempty subsets of a metric space $(X, d)$. We denote by $A_{0}$ and $B_{0}$ the following sets:

$$
\begin{aligned}
& A_{0}=\{x \in A: d(x, y)=d(A, B) \text { for some } y \in B\}, \\
& B_{0}=\{y \in B: d(x, y)=d(A, B) \text { for some } x \in A\},
\end{aligned}
$$

where $d(A, B)=\inf \{d(x, y): x \in A, y \in B\}$. 
Definition 3.1 Let $(A, B)$ be a pair of nonempty subsets of the metric space $(X, d)$ with $A_{0} \neq \emptyset$. Then the pair $(A, B)$ is said to have the P-property [31] if and only if

$$
\left\{\begin{array}{l}
d\left(x_{1}, y_{1}\right)=d(A, B), \\
d\left(x_{2}, y_{2}\right)=d(A, B),
\end{array} \quad \Rightarrow \quad d\left(x_{1}, x_{2}\right)=d\left(y_{1}, y_{2}\right),\right.
$$

where $x_{1}, x_{2} \in A$ and $y_{1}, y_{2} \in B$.

The following lemma is crucial in proving our best proximity point results.

Lemma 3.2 Let $(A, B)$ be a pair of nonempty closed subsets of a complete metric space $(X, d)$ such that $B_{0} \neq \emptyset$ and that $(A, B)$ satisfies the P-property. Then there exists a mapping $Q: B_{0} \rightarrow A_{0}$ satisfying

$$
d(x, Q x)=d(A, B) \quad \text { and } \quad d(Q x, Q y)=d(x, y) \quad \forall x, y \in B_{0} .
$$

Furthermore, $B_{0}$ is closed.

Proof Let $x \in B_{0}$, then we show that there exists a unique $y \in A_{0}$ such that $d(x, y)=d(A, B)$. To prove the uniqueness, let us assume that there exists $z \in A_{0}$ such that $d(x, y)=d(A, B)=$ $d(x, z)$. Since $(A, B)$ has the $P$-property, we have $d(y, z)=d(x, x)=0$ and so $y=z$. Let $y=$ $Q x$, then $d(x, Q x)=d(x, y)=d(A, B)$. Now, assume that $d(x, Q x)=d(A, B)=d(y, Q y)$, where $x, y \in B_{0}$. Then, by the $P$-property of $(A, B)$, we get $d(x, y)=d(Q x, Q y)$. Therefore, there exists a mapping $Q: B_{0} \rightarrow A_{0}$ such that

$$
d(x, Q x)=d(A, B) \quad \text { and } \quad d(Q x, Q y)=d(x, y) \quad \text { for each } x, y \in B_{0} .
$$

Now, we show that $B_{0}$ is closed. To prove the claim, let $\left\{x_{n}\right\}$ be a sequence in $B_{0}$ with $x_{n} \rightarrow x \in B$ (note that $B$ is closed). Since $A$ is a closed subset of a complete metric space, $d\left(Q x_{m}, Q x_{n}\right)=d\left(x_{m}, x_{n}\right)$ for each $m, n \in \mathbb{N}$ and $\left\{x_{n}\right\}$ is a Cauchy sequence, we deduce that $Q x_{n} \rightarrow y \in A$. Since $d\left(x_{n}, Q x_{n}\right)=d(A, B)$ for each $n \in \mathbb{N}$, we have

$$
d(x, y)=\lim _{n \rightarrow \infty} d\left(x_{n}, Q x_{n}\right)=d(A, B)
$$

and so $x \in B_{0}$. Hence, $B_{0}$ is closed.

Remark 3.3 It is clear that the mapping $Q$ in Lemma 3.2 is a bijection and for any $x \in A_{0}$, we have $d\left(x, Q^{-1} x\right)=d\left(Q\left(Q^{-1} x\right), Q^{-1} x\right)=d(A, B)$.

Definition 3.4 Let $(X, \preceq)$ be a preordered set. A non-self mapping $T: M \subseteq A \rightarrow B$ is said to be proximally non-decreasing if and only if

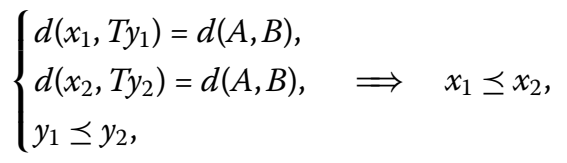

where $x_{1}, x_{2} \in A, y_{1}, y_{2} \in M$. 
The following lemma follows from Lemma 14 in [32].

Lemma 3.5 Let $(X, \preceq, d)$ be a preordered metric space, and let $T: A \rightarrow B$ be a non-self mapping such that $T A_{0} \subseteq B_{0}$. Let $(A, B)$ and $Q$ be as in the statement of Lemma 3.2. Suppose that $T: A_{0} \rightarrow B_{0}$ is proximally non-decreasing. Then the mapping $S: A_{0} \rightarrow A_{0}$ defined by $S x=Q T x$ for each $x \in A_{0}$ is non-decreasing.

The following lemma follows from Lemma 15 in [32].

Lemma 3.6 Let $(X, d, \preceq)$ be a preordered metric space $(A, B)$, and $Q$ be as in Lemma 3.2 and $T: A \rightarrow B$ be a non-self mapping such that $T A_{0} \subseteq B_{0}$. Suppose that there exist $x_{0}, x_{1} \in$ $A_{0}$ such that $d\left(x_{1}, T x_{0}\right)=d(A, B)$ and $x_{0} \preceq x_{1}$. Let the mapping $S: A_{0} \rightarrow A_{0}$ be defined by $S x=Q T x$ for each $x \in A_{0}$. Then $x_{0} \preceq S x_{0}$.

Now, we are ready to establish our best proximity point theorems.

Theorem 3.7 Let $(A, B)$ be a pair of nonempty closed subsets of a complete preordered metric space $(X, \preceq, d)$ such that $A_{0} \neq \emptyset$. Let $T: A \rightarrow B$ be a non-self mapping. Suppose that the following conditions hold:

(i) $T A_{0} \subseteq B_{0}$ and $(A, B)$ satisfy the P-property,

(ii) $T$ is continuous or $\left(A_{0}, \preceq, d\right)$ is regular,

(iii) $T$ is proximally non-decreasing,

(iv) there exist $x_{0}, x_{1} \in A_{0}$ such that

$$
d\left(x_{1}, T x_{0}\right)=d(A, B), \quad x_{0} \preceq x_{1},
$$

(v) For all $x, y \in A$ such that $x \leq y$, we have

$$
\begin{aligned}
d(T x, T y) \leq & \omega(d(x, y))+\delta(d(x, T x)-d(A, B), d(y, T y)-d(A, B), d(x, T y) \\
& -d(A, B), d(y, T x)-d(A, B))
\end{aligned}
$$

where $\omega \in \Omega, \delta \in \Delta$ and $\delta$ is non-decreasing in each of its variables.

Then $T$ has a best proximity point in $A$.

Proof Since $A_{0} \neq \emptyset$, so $B_{0} \neq \emptyset$. By Lemma 3.2, $B_{0}$ is closed and there exists an isometry $Q: B_{0} \rightarrow A_{0}$ which satisfies (17). Let $S: A_{0} \rightarrow A_{0}$ be defined by $S x=Q T x$ for each $x \in A_{0}$. Let $x, y \in A_{0}$ and $x \preceq y$, then from (18) we have

$$
\begin{aligned}
d(S x, S y)= & d(Q T x, Q T y)=d(T x, T y) \leq \omega(d(x, y))+\delta(d(x, T x)-d(A, B), d(y, T y) \\
& -d(A, B), d(x, T y)-d(A, B), d(y, T x)-d(A, B))
\end{aligned}
$$

but

$$
\begin{aligned}
d(x, T x)-d(A, B) & \leq d(x, S x)+d(S x, T x)-d(A, B)=d(x, S x)+d(Q T x, T x)-d(A, B) \\
& =d(x, S x)+d(A, B)-d(A, B)=d(x, S x)
\end{aligned}
$$


and

$$
\begin{aligned}
d(x, T y)-d(A, B) & \leq d(x, S y)+d(S y, T y)-d(A, B)=d(x, S y)+d(Q T y, T y)-d(A, B) \\
& =d(x, S y)+d(A, B)-d(A, B)=d(x, S y) .
\end{aligned}
$$

So, from (19) we have

$$
d(S x, S y) \leq \omega(d(x, y))+\delta(d(x, S x), d(y, S y), d(x, S y), d(y, S x))
$$

Thus $S$ is an ordered $(\omega, \delta, \preceq)$-contraction mapping of the first kind. Now conditions (ii), (iii) and (iv) with Lemma 3.5 and Lemma 3.6 imply that $S$ satisfies conditions (i), (ii) and (iii) of Theorem 2.6. Consequently, $S$ has a fixed point $x^{*} \in A_{0}$ such that $x^{*}=S x^{*}=Q T x^{*}$ and $Q^{-1} x^{*}=T x^{*}$. That is, $d\left(x^{*}, T x^{*}\right)=d\left(x^{*}, Q^{-1} x^{*}\right)=d\left(Q\left(Q^{-1} x^{*}\right), Q^{-1} x^{*}\right)=d(A, B)$. Thus $x^{*} \in A_{0}$ is the required best proximity point for $T$.

Corollary 3.8 Let $(A, B)$ be a pair of nonempty closed subsets of a complete metric space $(X, d)$ such that $A_{0} \neq \emptyset$ and $(A, B)$ satisfies the P-property. Let $T: A \rightarrow B$ such that for all $x, y \in A$,

$$
\begin{aligned}
d(T x, T y) \leq & \omega(d(x, y))+\delta(d(x, T x)-d(A, B), d(y, T y) \\
& -d(A, B), d(x, T y)-d(A, B), d(y, T x)-d(A, B)),
\end{aligned}
$$

where $\omega \in \Omega, \delta \in \Delta$ and $\delta$ is non-decreasing in each of its variables. Moreover, assume that $T A_{0} \subseteq B_{0}$. Then $T$ has a best proximity point in $A$.

Theorem 3.9 Let $(A, B)$ be a pair of nonempty closed subsets of a complete preordered metric space $(X, \preceq, d)$ such that $A_{0} \neq \emptyset$. Let $T: A \rightarrow B$ be a non-self mapping. Suppose that the following conditions hold:

(i) $T A_{0} \subseteq B_{0}$ and $(A, B)$ satisfy the P-property,

(ii) $T$ is continuous or $\left(A_{0}, \preceq, d\right)$ is regular,

(iii) $T$ is proximally non-decreasing,

(iv) there exist $x_{0}, x_{1} \in A_{0}$ such that

$$
d\left(x_{1}, T x_{0}\right)=d(A, B), \quad x_{0} \preceq x_{1},
$$

(v) For all $x, y \in A$ such that $y \preceq x$, we have

$$
\begin{aligned}
d(T x, T y) \leq & \omega(\max \{d(x, y), d(x, T x)-d(A, B), d(y, T y)-d(A, B) \\
& \left.\left.\frac{d(x, T y)+d(y, T x)}{2}-d(A, B)\right\}\right) \\
& +\delta(d(x, T x)-d(A, B), d(y, T y)-d(A, B), d(x, T y) \\
& -d(A, B), d(y, T x)-d(A, B))
\end{aligned}
$$

where $\omega \in \Omega$ is non-decreasing, $\delta \in \Delta$ and $\delta$ is non-decreasing in each of its variables.

Then $T$ has a best proximity point in $A$. 
Proof Since $A_{0} \neq \emptyset$, so $B_{0} \neq \emptyset$. By Lemma 3.2, $B_{0}$ is closed and there exists an isometry $Q: B_{0} \rightarrow A_{0}$ which satisfies (17). Let $S: A_{0} \rightarrow A_{0}$ be defined by $S x=Q T x$ for each $x \in A_{0}$. Let $x, y \in A_{0}$ and $y \preceq x$, then from (21) we have

$$
\begin{aligned}
d(S x, S y)= & d(Q T x, Q T y)=d(T x, T y) \\
\leq & \omega(\max \{d(x, y), d(x, T x)-d(A, B), d(y, T y)-d(A, B), \\
& \left.\left.\frac{d(x, T y)+d(y, T x)}{2}-d(A, B)\right\}\right) \\
& +\delta(d(x, T x)-d(A, B), d(y, T y)-d(A, B), d(x, T y) \\
& -d(A, B), d(y, T x)-d(A, B)) .
\end{aligned}
$$

Since $\omega$ is non-decreasing and $\delta$ is non-decreasing in each of its variables, in view of the proof of Theorem 3.7, we get

$$
d(S x, S y) \leq \omega(M(x, y))+\delta(d(x, S x), d(y, S y), d(x, S y), d(y, S x))
$$

for each $x, y \in A_{0}$, where $M(x, y)=\max \left\{d(x, y), d(x, S x), d(y, S y), \frac{d(x, S y)+d(y, S x)}{2}\right\}$. Thus $S$ is an ordered $(\omega, \delta, \preceq)$-contraction mapping of the second kind. Now conditions (ii), (iii) and (iv) with Lemma 3.5 and Lemma 3.6 imply that $S$ satisfies conditions (i), (ii) and (iii) of Theorem 2.9, so by Theorem $2.9 S$ has a fixed point $x^{*} \in A_{0}$ such that $x^{*}=S x^{*}=Q T x^{*}$ and $Q^{-1} x^{*}=T x^{*}$. Thus $d\left(x^{*}, T x^{*}\right)=d\left(x^{*}, Q^{-1} x^{*}\right)=d\left(Q\left(Q^{-1} x^{*}\right), Q^{-1} x^{*}\right)=d(A, B)$, as required.

Corollary 3.10 Let $(A, B)$ be a pair of nonempty closed subsets of a complete metric space $(X, d)$ such that $A_{0} \neq \emptyset$ and $(A, B)$ satisfies the P-property. Let $T: A \rightarrow B$ be such that for all $x, y \in A$,

$$
\begin{aligned}
d(T x, T y) \leq & \omega(\max \{d(x, y), d(x, T x)-d(A, B), d(y, T y)-d(A, B), \\
& \left.\left.\frac{d(x, T y)+d(y, T x)}{2}-d(A, B)\right\}\right) \\
& +\delta(d(x, T x)-d(A, B), d(y, T y)-d(A, B), d(x, T y) \\
& -d(A, B), d(y, T x)-d(A, B))
\end{aligned}
$$

where $\omega \in \Omega$ is non-decreasing, $\delta \in \Delta$ and $\delta$ is non-decreasing in each of its variables. Moreover, assume that $T A_{0} \subseteq B_{0}$. Then $T$ has a best proximity point in $A$.

\section{Remark 3.11}

(a) Theorem 3.9 is a generalization of Theorem 20 of Jleli et al. [32].

(b) From Lemma 2.2 and Theorem 3.7, we deduce the ordered version of Theorem 3.1 in [29].

From Lemma 2.2 and Corollary 3.8, we deduce the following result due to Samet [29]. 
Theorem 3.12 Let $(A, B)$ be a pair of nonempty closed subsets of a complete metric space $(X, d)$ such that $A_{0} \neq \emptyset,(A, B)$ satisfies the P-property. Let $T: A \rightarrow B$ such that for all $x, y \in A$,

$$
\begin{aligned}
d(T x, T y) \leq & \varphi(d(x, y))+\theta(d(x, T x)-d(A, B), d(y, T y)-d(A, B), d(x, T y) \\
& -d(A, B), d(y, T x)-d(A, B)),
\end{aligned}
$$

where $\varphi \in \Phi, \theta \in \Theta$. Moreover, assume that $T A_{0} \subseteq B_{0}$. Then $T$ has a best proximity point in $A$.

Now we provide the following example to show that Corollary 3.8 is an essential extension of the above mentioned theorem of Samet.

Example 3.13 Consider the complete metric space $X=[0,2] \times[0, \infty)$ with the Euclidean metric. Let $A=\{(0, x): 0 \leq x\}$ and $B=\{(2, y): 0 \leq y\}$. Then $d(A, B)=2, A_{0}=A, B_{0}=B$ and $(A, B)$ has the $P$-property.

Let $T: A \rightarrow B$ be defined by

$$
T(0, x)=(2, \ln (1+x)) \quad \text { for each } x \geq 0 .
$$

Let $\alpha(t)=\frac{\ln (1+t)}{t}$ for each $t>0$, let $\alpha(0)=0$ and let $\omega(t)=\alpha(t) t$ for each $t \in[0, \infty)$. Then, for all $x, y \in[0, \infty)$, we have

$$
\begin{aligned}
d(T(0, x), T(0, y)) & =|\ln (1+x)-\ln (1+y)| \\
& \leq \ln (1+|x-y|)=\omega(|x-y|)=\omega(d((0, x),(0, y))),
\end{aligned}
$$

and so the conditions of Corollary 3.8 are satisfied. Thus $T$ has a best proximity point (indeed, $P=(0,0)$ is a best proximity point of $T$ ). But we cannot invoke the above mentioned theorem of Samet to show that the mapping $T$ has a best proximity point in $A$ because $T$ is not an almost $(\varphi, \theta)$ contraction. On the contrary, assume that there exist $\varphi \in \Phi$ and $\theta \in \Theta$ such that for all $x, y \in A$,

$$
\begin{aligned}
d(T(0, x), T(0, y)) \leq & \varphi(d((0, x),(0, y)))+\theta(d((0, y), T(0, x)) \\
& -d(A, B), d((0, x), T(0, y))-d(A, B), d((0, x), T(0, x)) \\
& -d(A, B), d((0, y), T(0, y))-d(A, B)) .
\end{aligned}
$$

Letting $y=0$, we get

$$
\ln (1+x) \leq \varphi(x) \quad \text { for each } x \geq 0
$$

Let $f(x)=\ln (1+x)$ for each $x \in[0, \infty)$. Then it is easy to see that $f$ on $(0, \infty)$ is an increasing positive function. So, we have

$$
f(x) \leq \varphi(x) \text { for each } x \geq 0 .
$$


Let $x_{0}>0$, and let $x_{n+1}=f\left(x_{n}\right)$ for each $n \in \mathbb{N}$, then $\left\{x_{n}\right\}$ is a decreasing sequence of positive numbers. From the above, we have $x_{1}=f\left(x_{0}\right) \leq \varphi\left(x_{0}\right)$. Since $\varphi$ is non-decreasing, then from the above, we get

$$
x_{2}=f\left(x_{1}\right) \leq \varphi\left(x_{1}\right) \leq \varphi^{2}\left(x_{0}\right) .
$$

Proceeding in this manner, we get $x_{n} \leq \varphi^{n}\left(x_{0}\right)$ for each $n \in \mathbb{N}$, and so $\sum x_{n}$ is convergent (note that $\sum \varphi^{n}\left(x_{0}\right)$ is convergent). Let $0<c<\min \left\{x_{1}, 1\right\}$ be a constant. Now we show that

$$
x_{n}>\frac{c}{n} \text { for each } n \in \mathbb{N} .
$$

Obviously, the inequality holds for $n=1$. Now we proceed by induction. Assume that (24) holds for $n \in \mathbb{N}$. Then we have

$$
x_{n+1}=f\left(x_{n}\right) \geq f\left(\frac{c}{n}\right)=\ln \left(1+\frac{c}{n}\right) .
$$

Then, from the above, we obtain (note that $\ln (1+x) \geq x-\frac{x^{2}}{2}$ )

$$
\begin{aligned}
x_{n+1} \geq & \ln \left(1+\frac{c}{n}\right) \geq \frac{c}{n}-\frac{c^{2}}{2 n^{2}} \\
= & \frac{c}{n+1}+\frac{c}{n(n+1)}-\frac{c^{2}}{2 n^{2}} \geq \frac{c}{n+1},
\end{aligned}
$$

and so (24) holds for each $n \in \mathbb{N}$. Since $x_{n}>\frac{c}{n}$ for each $n \in \mathbb{N}$ and $\sum \frac{c}{n}=\infty$, then we get $\sum x_{n}=\infty$, a contradiction.

\section{Competing interests}

The authors declare that they have no competing interests.

\section{Authors' contributions}

All authors contributed equally and significantly in writing this article. All authors read and approved the final manuscript.

\section{Author details}

${ }^{1}$ Department of Pure Mathematics, University of Shahrekord, Shahrekord, 88186-34141, Iran. ${ }^{2}$ School of Mathematics, Institute for Research in Fundamental Sciences (IPM), P.O. Box 19395-5746, Tehran, Iran. ${ }^{3}$ Department of Mathematics, University of Isfahan, Isfahan, 81745-163, Iran. ${ }^{4}$ Department of Mathematics, King Abdulaziz University, P.O. Box 80203, Jeddah, 21589, Saudi Arabia.

\section{Acknowledgements}

The first author was partially supported by a grant from IPM (No. 92470412). The second author was partially supported by a grant from IPM (No. 92550414). The first and the second author were also partially supported by the Center of Excellence for Mathematics, University of Shahrekord, Iran. This article was funded by the Deanship of Scientific Research (DSR), King Abdulaziz University, Jeddah. Therefore, the fourth author acknowledges with thanks DSR, KAU for financial support.

Received: 15 July 2013 Accepted: 9 October 2013 Published: 07 Nov 2013

\section{References}

1. Amini-Harandi, A: Coupled and tripled fixed point theory in partially ordered metric spaces with application to initial value problem. Math. Comput. Model. (2012). doi:10.1016/j.mcm.2011.12.006

2. Amini-Harandi, A: Fixed and coupled fixed points of a new type set-valued contractive mappings in complete metric spaces. Fixed Point Theory Appl. 2012, Article ID 215 (2012). doi:10.1186/1687-1812-2012-215

3. Babu, GVR, Sandhya, ML, Kameswari, MVR: A note on a fixed point theorem of Berinde on weak contractions. Carpath. J. Math. 24(1), 8-12 (2008)

4. Berinde, V, Pacurar, M: Fixed points and continuity of almost contractions. Fixed Point Theory 9, 23-34 (2008) 
5. Berinde, V: Some remarks on fixed points theorem for Ćirić-type almost contractions. Carpath. J. Math. 25, 157-162 (2009)

6. Ćirić, L, Abbas, M, Saadati, R, Hussain, N: Common fixed points of almost generalized contractive mapping in ordered metric spaces. Appl. Math. Comput. 217, 5784-5789 (2011)

7. Fan, K: Extensions of two fixed point theorems of F. E. Browder. Math. Z. 112, 234-240 (1969)

8. Prolla, JB: Fixed point theorems for set valued mappings and existence of best approximations. Numer. Funct. Anal. Optim. 5, 449-455 (1982/1983)

9. Hussain, N, Khan, AR, Agarwal, RP: Krasnosel'skii and Ky Fan type fixed point theorems in ordered Banach spaces. J. Nonlinear Convex Anal. 11(3), 475-489 (2010)

10. Hussain, N, Khan, AR: Applications of the best approximation operator to $*$-nonexpansive maps in Hilbert spaces. Numer. Funct. Anal. Optim. 24(3-4), 327-338 (2003)

11. Takahashi, W: Fan's existence theorem for inequalities concerning convex functions and its applications. In: Ricceri, B, Simons, S (eds.) Minimax Theory and Applications, pp. 597-602. Kluwer Academic, Dordrecht (1998)

12. Abkar, A, Gabeleh, M: The existence of best proximity points for multivalued mappings. Rev. R. Acad. Cienc. Exactas Fís. Nat., Ser. A Mat. (2013). doi:10.1007/s13398-012-0074-6

13. Abkar, A, Gabeleh, M: Best proximity points for cyclic mappings in ordered metric spaces. J. Optim. Theory Appl. 150(1), 188-193 (2011). doi:10.1007/s10957-011-9818-2

14. Amini-Harandi, A: Best proximity points theorems for cyclic strongly quasi-contraction mappings. J. Glob. Optim. (2013). doi:10.1007/s10898-012-9953-9

15. Amini-Harandi, A: Best proximity points for proximal generalized contractions in metric spaces. Optim. Lett. (2013). doi:10.1007/s11590-012-0470-z

16. Amini-Harandi, A: Common best proximity points theorems in metric spaces. Optim. Lett. (2012) doi:10.1007/s11590-012-0600-7

17. Amini-Harandi, A, Hussain, N, Akbar, F: Best proximity point results for generalized contractions in metric spaces. Fixed Point Theory Appl. 2013, Article ID 164 (2013)

18. Caballero, C, Harjani, J, Sadarangani, K: A best proximity point theorem for Geraghty-contraction. Fixed Point Theory Appl. 2012, Article ID 231 (2012). doi:10.1186/1687-1812-2012-231

19. Eldred, AA, Veeramani, P: Existence and convergence of best proximity points. J. Math. Anal. Appl. 323, 1001-1006 (2006)

20. Hussain, N, Kutbi, MA, Salimi, P: Best proximity point results for modified $\alpha$ - $\psi$-proximal rational contractions. Abstr. Appl. Anal. 2013, Article ID 927457 (2013)

21. Suzuki, T, Kikkawa, M, Vetro, C: The existence of best proximity points in metric spaces with the property UC. Nonlinear Anal. 71, 2918-2926 (2009)

22. Jleli, M, Samet, B: Best proximity point for $\alpha$ - $\psi$-proximal contractive type mappings and applications. Bull. Sci. Math (2013). doi:10.1016/j.bulsci.2013.02.003

23. Kirk, WA, Reich, S, Veeramani, P: Proximinal retracts and best proximity pair theorems. Numer. Funct. Anal. Optim. 24, 851-862 (2003)

24. Mongkolkeha, C, Kumam, P: Best proximity point theorems for generalized cyclic contractions in ordered metric spaces. J. Optim. Theory Appl. (2012). doi:10.1007/s10957-012-9991-y

25. Sadiq Basha, S: Best proximity points: global optimal approximate solution. J. Glob. Optim. 49, 15-21 (2011)

26. Sadiq Basha, S: Best proximity points: optimal solutions. J. Optim. Theory Appl. 151, 210-216 (2011)

27. Sadiq Basha, S: Best proximity point theorems: unriddling a special nonlinear programming problem. Top (2012). doi:10.1007/s11750-012-0269-1

28. Agarwal, RP, Hussain, N, Taoudi, MA: Fixed point theorems in ordered Banach spaces and applications to nonlinear integral equations. Abstr. Appl. Anal. 2012, Article ID 245872 (2012)

29. Samet, B: Some results on best proximity points. J. Optim. Theory Appl. (2013). doi:10.1007/s10957-013-0269-9

30. Agarwal, RP, El-Gebeily, MA, O’Regan, D: Generalized contractions in partially ordered metric spaces. Appl. Anal. 87(1), 109-116 (2008)

31. Sankar Raj, V: A best proximity point theorems for weakly contractive non-self mappings. Nonlinear Anal. $\mathbf{7 4}$ 4804-4808 (2011)

32. Jleli, M, Karapinar, E, Samet, B: On best proximity points under the P-property on partially ordered metric spaces. Abstr. Appl. Anal. 2013, Article ID 150970 (2013)

10.1186/1687-1812-2013-263

Cite this article as: Amini-Harandi et al.: Some new results on fixed and best proximity points in preordered metric spaces. Fixed Point Theory and Applications 2013, 2013:263 